\title{
Renal Autotransplantation in a Patient With Resistant Renal Artery Stenosis
}

\author{
Takuya Wakamiya ${ }^{\mathrm{a}, \mathrm{d}}$, Yusuke Nakano ${ }^{\mathrm{a}}$, Tatsunori Hokosaki ${ }^{\mathrm{a}}$, Mari Iwamoto ${ }^{\mathrm{a}}$, Jyunichi Teranishi ${ }^{\mathrm{b}}$, \\ Masako Otanic
}

\begin{abstract}
We report the case of a 5-year-old boy who presented to our hospital with renovascular hypertension $(\mathrm{RVH})$ resulting from right renal artery stenosis (RAS). We performed percutaneous transluminal renal angioplasty (PTRA) on the right RAS. Although hypertension improved after PTRA, restenosis occurred and aggravated hypertension was observed 2 - 3 months later. PTRA was performed again and repeated three times because of restenoses. We subsequently transected the renal arteries and performed renal autotransplantation. The postoperative course was uneventful and hypertension improved. Pathology results showed intimal fibroplasias. More than 1 year and 3 months after transplant, restenosis of the renal artery had not occurred. Successful renal autotransplantation after the frequent PTRA has not been previously reported, and intimal fibromuscular dysplasia (FMD) is rare. Restenosis frequently occurs after PTRA in patients with renovascular hypertension, and renal autotransplantation is an effective treatment in children.
\end{abstract}

Keywords: Fibromuscular dysplasia; Percutaneous transluminal renal angioplasty; Recurrent stenosis; Renal autotransplantation; Renovascular hypertension

\section{Introduction}

The prevalence of hypertension in children is $1-5 \%$ and renovascular hypertension (RVH) accounts for $5-10 \%$ of the cases [1]. RVH is often caused by renal artery stenosis (RAS). In children, the most common cause of RAS is fibromuscular dysplasia (FMD). RVH resulting from FMD is potentially

Manuscript accepted for publication April 28, 2016

aDepartment of Pediatric Cardiology, Yokohama City University School of Medicine, Yokohama, Japan

bDepartment of Urology and Renal Transplant, Yokohama City University Medical Center, Yokohama, Japan

'Division of Diagnostic Pathology, Yokohama City University Medical Center, Yokohama, Japan

${ }^{\mathrm{d} C}$ Corresponding Author: Takuya Wakamiya, Department of Pediatric Cardiology, Yokohama City University School of Medicine, 3-9 Fukuura, Kanazawaku, Yokohama 236-0004, Japan. Email: takuya0442 @hotmail.co.jp

doi: http://dx.doi.org/10.14740/jmc2492w correctable, and percutaneous transluminal renal angioplasty (PTRA) is often an effective treatment for FMD, with a high technical and clinical success rate [2]. PTRA is preferred in children because it is less invasive than open surgery.

However, there are some patients who are resistant to PTRA. In such cases, repeat PTRA, a stent or open surgery can be considered. Open surgery includes an arterial bypass (prosthesis or vein), autotransplantation or primary nephrectomy.

In children, autologous transplantation showed better arterial bypass than a prosthesis or vein and it can preserve the kidney [3]. We report a case of FMD with multiple restenosis after PTRA that was successfully treated with autologous renal transplant.

\section{Case Report}

A 5-year-old male patient presented to the emergency department with chief complaints of headache and vomiting. Significant hypertension $(210 / 180 \mathrm{~mm} \mathrm{Hg})$ was incidentally detected. His height was $110 \mathrm{~cm}(+0.5 \mathrm{SD})$ and weight was $18 \mathrm{~kg}(0 \mathrm{SD})$. The physical examination showed continuous murmur sounds in the right upper abdomen. Chest X-rays and electro-cardiogram results were normal. Laboratory test results showed that blood urea nitrogen (BUN) was $21 \mathrm{mg} / \mathrm{dL}$ and creatinine was $0.33 \mathrm{mg} / \mathrm{dL}$. Sodium was $132 \mathrm{mEq} / \mathrm{L}$, potassium was 3.4 $\mathrm{mEq} / \mathrm{L}$ and the glomerular filtration rate (GFR) was $74 \mathrm{~mL} /$ $\mathrm{min} / 1.73 \mathrm{~m}^{2}$ (normal: $>90 \mathrm{~mL} / \mathrm{min} / 1.73 \mathrm{~m}^{2}$ ). Elevated plasma renin activity (PRA; $120 \mathrm{ng} / \mathrm{mL} / \mathrm{h}$; reference value: $0.2-2.7$ $\mathrm{ng} / \mathrm{mL} / \mathrm{h}$ ) and serum aldosterone ( $46 \mathrm{ng} / \mathrm{dL}$; reference value: 2 - $13 \mathrm{ng} / \mathrm{dL}$ ) were also identified. Computed tomography angiography showed an 8-mm long stenosis of $0.7 \mathrm{~mm}$ thick in the right renal artery. The left renal artery was intact (Fig. 1). The patient was diagnosed with RVH secondary to RAS.

Immediate treatment with intravenous nifedipine was initiated. Once the patient's systolic blood pressure decreased to approximately $130 \mathrm{~mm} \mathrm{Hg}$, nifedipine was switched to the oral form. The medication for hypertension was then switched to amlodipine (7.5 $\mathrm{mg}$ once daily), enalapril (6.5 $\mathrm{mg}$ twice daily) and losartan (20 mg twice daily).

Two-dimensional echocardiography revealed left ventricular hypertrophy, and the thickness of the left ventricular wall was $7.5-10 \mathrm{~mm}$, slightly above the normal limit. Abdominal echography showed that peak flow velocity of the left renal artery was $0.9 \mathrm{~m} / \mathrm{s}$, but that of the right renal artery was $3.2 \mathrm{~m} / \mathrm{s}$. Renal scintigraphy using $\left({ }^{99 \mathrm{~m}} \mathrm{Tc}\right)$-diethylenetriamine- 


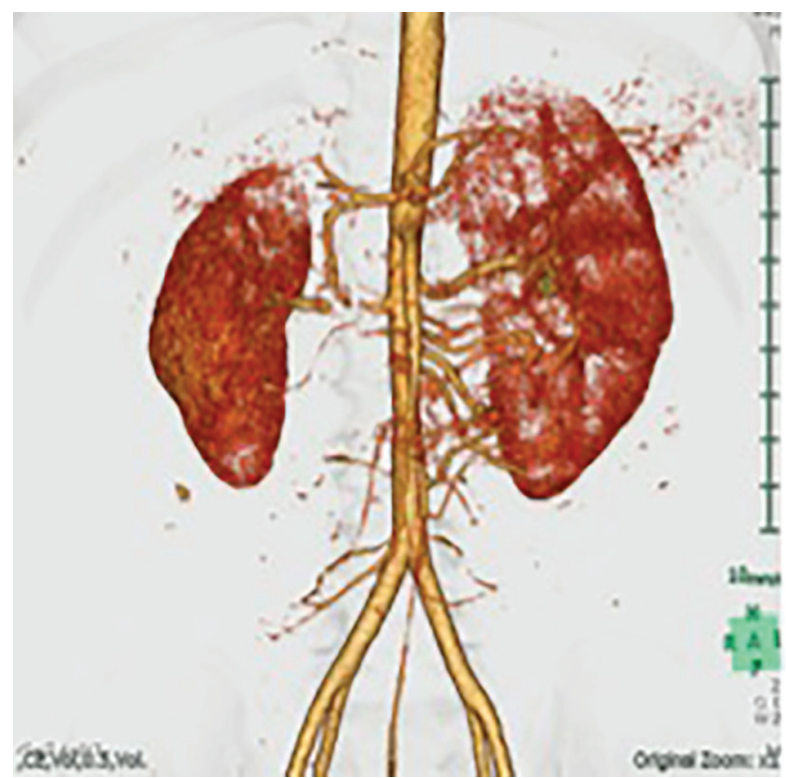

Figure 1. A three-dimensional computed tomography image showing the right renal artery with severe proximal stenosis and atrophy of the right kidney.

pentaacetic acid ( ${ }^{99 \mathrm{~m}}$ Tc-DTPA) showed a severe functional decline in the right kidney (GFR: $10.2 \mathrm{~mL} / \mathrm{h}$ in the right kidney; $48.9 \mathrm{~mL} / \mathrm{h}$ in the left kidney).

Despite administration of oral anti-hypertensive agents, systemic hypertension continued for 2 months, and treatment with PTRA was considered. Angiography showed three right renal arteries, and the central right renal artery was severely narrowed (Fig. 2).

PRA was measured by selective venous blood sampling during catheterization. The results were as follows: right renal vein $70 \mathrm{ng} / \mathrm{mL} / \mathrm{h}$ (reference value: 0.2 - $2.7 \mathrm{ng} / \mathrm{mL} / \mathrm{h}$ ), left renal vein $47 \mathrm{ng} / \mathrm{mL} / \mathrm{h}$, upper inferior vena cava $50 \mathrm{ng} / \mathrm{mL} / \mathrm{h}$, and lower inferior vena cava $44 \mathrm{ng} / \mathrm{mL} / \mathrm{h}$. These results can be affected by inhibition of angiotensin-converting enzyme.

PTRA was performed under generalized anesthesia. The narrowest segment was $0.6 \mathrm{~mm}$, stenosis length was $10 \mathrm{~mm}$ and poststenotic dilatation was $4.3 \mathrm{~mm}$. The balloon used was SHIDEN $(2.0 \times 20 \mathrm{~mm} / 6 \mathrm{~atm}$ and $2.5 \times 20 \mathrm{~mm} / 8 \mathrm{~atm})($ Kaneka Medics, Osaka, Japan). The narrowest segment was dilated to $1.7 \mathrm{~mm}$.

After intervention, systolic blood pressure dropped to 110 - $120 \mathrm{~mm} \mathrm{Hg}$. However, 3 months later, the patient's systolic blood pressure increased to $130 \mathrm{~mm} \mathrm{Hg}$, and restenosis of the artery was identified at ultrasound examination.

PTRA was attempted four times between 14 months using different catheters, as detailed below. Restenosis of the renal artery occurred each time.

The second PTRA catheter was a high-pressure balloon (Bandicot; $2.5 \times 20 \mathrm{~mm} / 14 \mathrm{~atm}, 3.0 \times 20 \mathrm{~mm} / 16 \mathrm{~atm}$, and 3.5 $\times 20 \mathrm{~mm} / 10 \mathrm{~atm})$ (Kaneka Medics, Osaka, Japan). The narrowest segment was dilated from 0.6 to $2.2 \mathrm{~mm}$.

The third PTRA device was an Angio sculpt balloon $(3.0 \times$ $20 \mathrm{~mm} / 10 \mathrm{~atm}$ and $3.5 \times 20 \mathrm{~mm} / 18 \mathrm{~atm}$ ) (AngioScore, Fremont, CA, USA), which had a slip-prevention function, providing a precise and predictable dilatation across a wide range of lesion types. The narrowest segment was dilated from 0.9 to $2.9 \mathrm{~mm}$.

The fourth PTRA was performed with a small cutting balloon $(2.5 \times 150 \mathrm{~mm} / 12 \mathrm{~atm}, 3.0 \times 150 \mathrm{~mm} / 12 \mathrm{~atm}$, and $3.5 \times$ $150 \mathrm{~mm} / 12 \mathrm{~atm})$. The narrowest segment was dilated from 0.9 to $3.4 \mathrm{~mm}$.

After the fourth PTRA, GFR improved to $118 \mathrm{~mL} /$ $\mathrm{min} / 1.73 \mathrm{~m}^{2}$, and ${ }^{99 \mathrm{~m}} \mathrm{Tc}-\mathrm{DTPA}$ showed improvement of renal function (GFR: $16.6 \mathrm{~mL} / \mathrm{h}$ in the right kidney; $56.8 \mathrm{~mL} / \mathrm{h}$ in the left kidney).

However, restenosis of the renal artery occurred 4 months after the last PTRA. Therefore, renal autotransplantation was
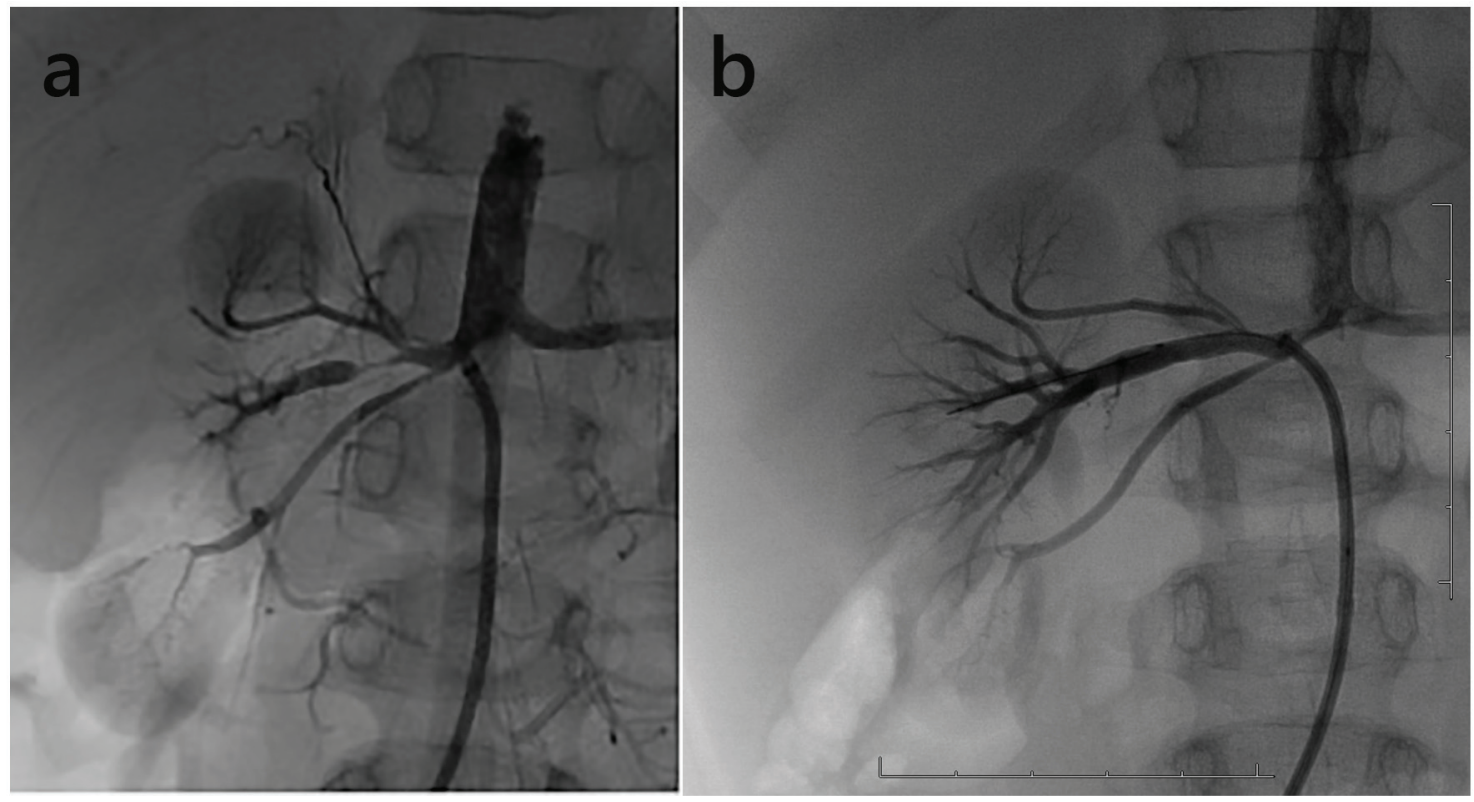

Figure 2. (a) Angiography showed a long tubular stenosis of the right renal artery. (b) Angiographic appearances after PTRA. 

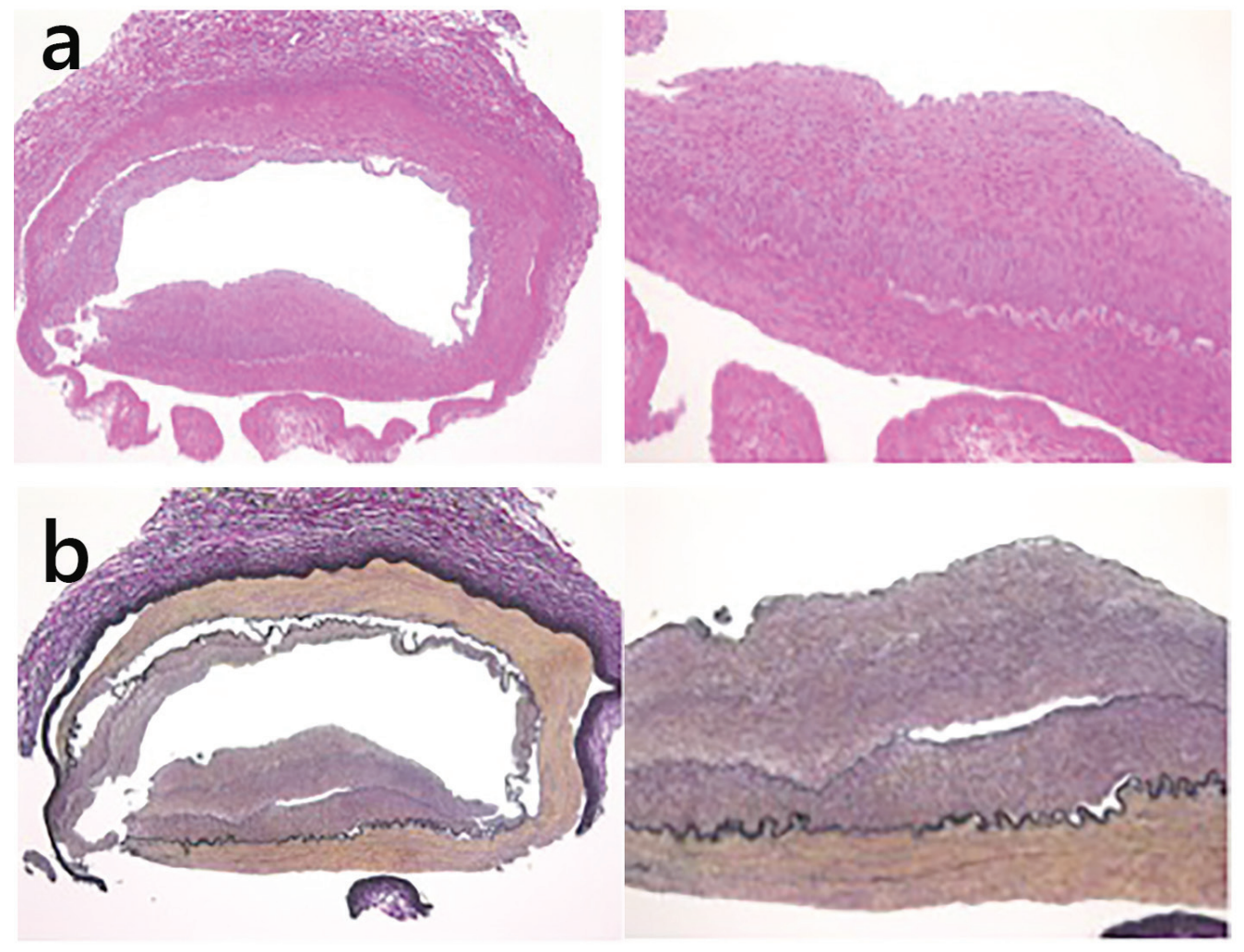

Figure 3. (a) Intimal fibromuscular dysplasia was revealed at the origin of the right renal artery, using hematoxylin and eosin staining. (b) Intimal thickening of the renal artery consisted of fibroelastic proliferation and no inflammatory cell infiltration (Elastica van Gieson staining).

performed 8 months after the fourth PTRA, when the patient was 7 years old.

Because the right kidney tissue was normal on biopsy, we anticipated that the kidney could be preserved. An autologous renal transplant was performed in the right ilium. We did not attach a handle to the urinary tract. The right kidney was reserved upside down. After resecting the narrow segment, the central renal artery and the right upper renal artery were attached side to end, and we created an end-to-end anastomosis between the central renal artery and internal iliac artery. The right lower renal branch was anastomosed end to end with the superior vesical artery. Right renal artery pathology results showed intimal elastic fibrous thickening and inflammatory cell infiltrates, and cholesterol was absent (Fig. 3). Thus, intimal type FMD was diagnosed.

After renal autotransplantation, the systolic blood pressure decreased to $110-120 \mathrm{~mm} \mathrm{Hg}$ using only amlodipine (5 $\mathrm{mg}$ ). Dipyridamole was administered for anticoagulation. At a follow-up visit 1 year and 3 months after the surgery, blood pressure had normalized at 120/70 $\mathrm{mm} \mathrm{Hg}$ using amlodipine $(2.5 \mathrm{mg})$.

\section{Discussion}

Causes of RAS include arteriosclerosis, FMD, inflammatory artery diseases, vascular Ehlers-Danlos, Williams' syndromes and type I neurofibromatosis [4]. Arteriosclerosis is the most common cause of renal artery stenosis in adults, while most renal artery stenosis cases in children are caused by FMD $[5,6]$.

In our patient, restenosis occurred despite frequent PTRA, even using the cutting balloon, which is a newer technology.

The success rate of PTRA depends upon the underlying disease. For FMD, aortoarteritis and mid-aortic syndrome, long-term results of PTRA are good, whereas PTRA performed in patients with underlying neurofibromatosis does not have good results [5]. The renal artery restenosis rate in children varies between $7.4 \%$ and $40.9 \%$, and restenosis occurs several months after an initial PTRA [6, 7].

The location of the stenotic lesion has been reported to affect the outcome of PTRA. Mid- or distal sites have a higher success rate than proximal lesions [5].

The intimal type of FMD is resistant to PTRA [8]. Balloon angioplasty can cause injury to the vascular wall, which results in intimal hyperplasia [9]. Pathological findings for our patient showed dissociation of the medial layer, and therefore, certain effects of PTRA were identified. The renal function was improved by PTRA and the patient was able to keep his kidney following surgery. However, it is possible that the dissociation caused restenosis by damaging the intimal layer.

Most FMD lesions are often in the media, and they have a 
"string of beads" appearance on angiography [4, 10]. Intimal fibroplasia has a frequency of less than $10 \%$ in FMD patients, with a tubular type narrow segment that has a long concentric stenosis on angiography $[4,10]$. Our patient's angiographic features included a long concentric stenosis lesion, and this stenosis image suggested intimal FMD. Our patient's pathology results showed intimal thickening of the renal artery that was expected in the angiographic image.

When intimal FMD is suspected from angiography and if it is resistant to PTRA, newer technologies, such as a cutting balloon, should be used at an early stage.

Stent placement or surgical treatment has been used in cases of repeated restenosis, but we chose surgical treatment because endovascular prostheses cannot change in size along with normal vessel growth, and there might be a size mismatch over time.

There have been few reports of long-term anastomotic site results. Kimura et al reported that the surgical treatment success rate of 25 patients was $88 \%$ over a 24 -year period. Autologous aorta-renal bypass or direct reimplantation showed better renal artery patency, and there was less likelihood of a secondary nephrectomy than with a prosthetic aorto-renal bypass [3]. We followed up with our patient 1 year and 3 months after the operation. His blood pressure was well controlled using only one antihypertensive medication.

\section{Conclusions}

Renal autotransplantation is a useful treatment strategy for the patients with RAS that is resistant to treatment using PTRA. PTRA is effective as a treatment and has a renal protective effect until surgical treatment.

\section{Conflicts of Interest}

The authors have no conflict of interest to disclose.

\section{References}

1. Tullus K, Brennan E, Hamilton G, Lord R, McLaren CA, Marks SD, Roebuck DJ. Renovascular hypertension in children. Lancet. 2008;371(9622):1453-1463.

2. Towbin RB, Pelchovitz DJ, Cahill AM, Baskin KM, Meyers KE, Kaplan BS, McClaren CA, et al. Cutting balloon angioplasty in children with resistant renal artery stenosis. J Vasc Interv Radiol. 2007;18(5):663-669.

3. Kimura H, Sato O, Deguchi JO, Miyata T. Surgical treatment and long-term outcome of renovascular hypertension in children and adolescents. Eur J Vasc Endovasc Surg. 2010;39(6):731-737.

4. Plouin PF, Perdu J, La Batide-Alanore A, Boutouyrie P, Gimenez-Roqueplo AP, Jeunemaitre X. Fibromuscular dysplasia. Orphanet J Rare Dis. 2007;2:28.

5. Konig K, Gellermann J, Querfeld U, Schneider MB. Treatment of severe renal artery stenosis by percutaneous transluminal renal angioplasty and stent implantation: review of the pediatric experience: apropos of two cases. Pediatr Nephrol. 2006;21(5):663-671.

6. Shroff R, Roebuck DJ, Gordon I, Davies R, Stephens S, Marks S, Chan M, et al. Angioplasty for renovascular hypertension in children: 20-year experience. Pediatrics. 2006;118(1):268-275.

7. Zhu G, He F, Gu Y, Yu H, Chen B, Hu Z, Liang W, et al. Angioplasty for pediatric renovascular hypertension: a 13year experience. Diagn Interv Radiol. 2014;20(3):285-292.

8. Meuse MA, Turba UC, Sabri SS, Park AW, Saad WE, Angle JF, Matsumoto AH. Treatment of renal artery fibromuscular dysplasia. Tech Vasc Interv Radiol. 2010;13(2):126133.

9. Stuckle CA, Laufer U, Kirchner J, Muller H, Adams S, Adamietz IA, Liermann DD. Successful treatment of intimal hyperplasia in renal arteries by endovascular brachytherapy. Cardiovasc Radiat Med. 2001;2(2):114-118.

10. Slovut DP, Olin JW. Fibromuscular dysplasia. N Engl J Med. 2004;350(18):1862-1871. 